\title{
Comunicação popular, alternativa e comunitária: um estado da arte
}

DOI: 10.1590/1809-58442017115

\section{Nivea Canalli Bona}

(Universidade Metodista de São Paulo, Escola de Comunicação, Educação e Humanidades, Núcleo de Estudos em Comunicação Comunitária e Local. São Bernardo do Campo - SP, Brasil)

OTRE, Maria Alice Campagnoli. Comunicação popular, alternativa e comunitária: um olhar sobre 40 anos de pesquisas no Brasil. São Paulo: Fundação JK, 2016. 295p.

A definição da expressão “Estado da Arte” reflete bem a necessidade do ser humano de estabelecer um conhecimento total sobre determinado assunto. É como se, em meio às infinitas informações que estão sendo divulgadas, partilhadas e democratizadas, fosse possível reuni-las nos antigos compêndios que continham tudo que foi estudado em cada área do conhecimento. Tarefa naturalmente impossível em dias como os nossos. Mas há os que se esforçam para

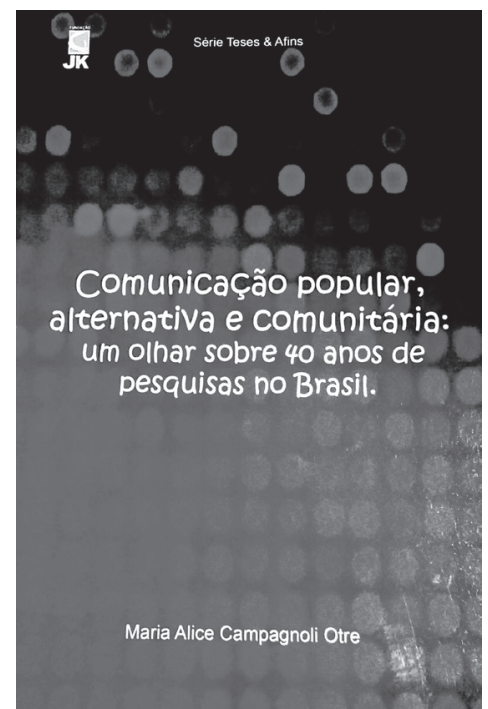
trazer um panorama de determinados ciclos. Esses traçados ajudam, e muito, a ter uma noção de tendência, de movimentações coletivas. E, dessa forma, contribuem para ajustar as velas, porém, mais do que isso, entender as conclusões dos estudos que acabam sendo compartimentados pelo necessário exercício da profundidade epistemológica. É como se tivéssemos uma fotografia aérea que reúne os produtos de determinada fatia temporal.

A obra Comunicação popular, alternativa e comunitária: um olhar sobre 40 anos de pesquisas no Brasil reflete esse intuito, o de ofertar uma visão sobre essa subárea da Comunicação Social e teve sua origem na tese de doutoramento da autora, Maria Alice Campagnoli Otre: A pesquisa acadêmica sobre Comunicação Popular, Alternativa e Comunitária no Brasil: análise de dissertações e teses produzidas em Programas de Pósgraduação em Comunicação entre 1972 - 2012.

Ao contrário de uma das percepções desse trabalho, a qual evidencia um descuido pela metodologia utilizada nos estudos da área da comunicação popular, alternativa e comunitária (CPAC), a obra apresenta claramente o caminho metodológico perseguido. 
Utiliza-se da “pesquisa da pesquisa” (BONIN, 2008) para identificar os trabalhos que poderiam fazer parte do escopo de estudo; depois a autora realiza uma busca exploratória nos bancos de dissertações e teses dos 44 programas de pós-graduação (PPGs) em Comunicação no Brasil, na época, utilizando-se do repositório da Capes (que disponibiliza produções de 1987 a 2012) como fonte primária; por fim, vai à origem dos PPGs que tiveram estudos na subárea entre 1972 e 1987. Dessa busca exploratória no banco da Capes, surgiram 9787 dissertações e teses que responderam por um grupo de expressões como “popular”, “alternativo”, “comunitário”, entre outras afeitas. Após análise de títulos, de resumos e de textos completos, a fim de filtrar os trabalhos que continham a subárea como foco principal, chegou-se ao corpus de 87 dissertações e 15 teses, totalizando 102 pesquisas publicadas sobre CPAC.

A partir da análise documental e de conteúdo desses estudos, Otre nos brinda com riquíssimos resultados que trazem a interpretação do “eixo principal de investigação”, da “denominação usada pelo pesquisador”, apuração se o trabalho foi teórico ou empírico, o suporte (tipo midiático) estudado, momento histórico, explicitação metodológica e tipos ou técnicas de pesquisa. Além disso, foi realizada uma análise qualitativa das 15 teses, o que aprofundou a reflexão a partir de outras sete categorias. Por fim, uma lista com os autores mais presentes e citados nessas pesquisas aponta a grande influência de autores brasileiros e latino-americanos.

A simples descrição dos passos metodológicos utilizados já nos mostra o hercúleo esforço em alcançar a totalidade das investigações no período. A descrição da metodologia é só o primeiro capítulo. É da análise desse material todo que a obra trata.

O segundo capítulo é divido em dois subcapítulos. O primeiro traz o contexto histórico (com foco nos fluxos comunicacionais por meio dos informes Macbride e Nomic e nos movimentos sociais, sujeitos dessa comunicação). O segundo subcapítulo apresenta as linhas teóricas e contextualiza os conceitos da área, trazendo luz, especificamente, para o que seria a "Imprensa Alternativa”, a “Comunicação Popular Alternativa” e a “Comunicação Popular e Comunitária”. O interessante dessa seção da obra é que autora apresenta os conceitos de determinados estudiosos situando-os também como os produtores de investigações que foram analisadas. Assim, como exemplo, é abordada a proposta de Regina Festa na "primeira dissertação de mestrado em comunicação popular, alternativa e comunitária”. Ou ainda o trabalho de Pedro Gilberto Gomes, "produtor da terceira dissertação de mestrado na subárea” (p.55-57).

O terceiro capítulo traz a análise de conteúdo realizada tanto nas dissertações quanto nas teses selecionadas. Abundante em volume de informação, o capítulo se subdivide em períodos históricos, já que é explícito que a CPAC tem seu caminho traçado pelos grupos afetados pelo momento em que estão inseridos. Assim, o primeiro subcapítulo traz a análise 
dos trabalhos defendidos no período de 1972 a 1992 ("Reflexões fundantes para a CPAC no Brasil”); o segundo traz de 1992 a 2002 (“Legalização e democratização em destaque”); o terceiro, de 2003 a 2007 (“Testando as experiências e forjando identidades”) e o quarto apresenta de 2008 a 2012 (“Na contramão tecnológica, o grito por cidadania”).

A reflexão sobre a análise qualitativa das 15 teses defendidas entre 1972 e 2012 aparece no capítulo quatro, formado por sete subcapítulos que tratam da identidade dos pesquisadores, dos grupos estudados, os objetivos dessa comunicação e os autores referência e conceitos importantes para a subárea, entre outros.

No capítulo destinado às conclusões, o leitor poderá encontrar dados preciosos, como a constatação de que os pesquisadores determinam os conceitos teóricos a partir das experiências - foram encontradas 24 diferentes formas de se nomear a subárea; o quanto frequente é a técnica metodológica do estudo de caso ou ainda como, no decorrer dos anos, os estudos foram estabelecendo maior rigor na definição metodológica.

Para quem espera ter uma publicação afastada da raiz e da origem dessa Comunicação “pé-no-barro", urge informar que irá se frustrar. Quem estuda CPAC sabe que essas iniciativas estão intimamente ligadas com uma luta visceral de grupos menos afortunados contra um sistema que privilegia a lógica da exploração de uns para o bem viver dos outros. A obra aponta, teoricamente e por meio dos resultados encontrados, o que deveria ser óbvio para todo pesquisador da área: há um lado a ser tomado. E essa posição epistemológica não pode diminuir o rigor das investigações a serem realizadas nas próximas décadas já que as conclusões aqui fornecem a direção: a metodologia precisa ser clara, testável, intencional, problematizada e racional.

\section{Nivea Canalli Bona (autora da resenha)}

Jornalista pela PUC- PR, mestre em Comunicação Social pela Universidade Metodista de São Paulo (UMESP) e doutora em Comunicação Social pela Universidade do Vale do Rio dos Sinos (Unisinos), de São Leopoldo - RS. É integrante dos seguintes grupos de pesquisa: Núcleo de Estudos em Comunicação Comunitária e Local - Comuni (Umesp); Grupo de Pesquisa em Processos Comunicacionais: epistemologia, midiatização, mediações e recepção - Processocom (Unisinos) e do Grupo de Pesquisa em Jornalismo Alternativo na Era Digital (Uninter). Vive atualmente em Bar Harbor, Maine, Estados Unidos da América. E-mail: bonanivea@gmail.com 